\title{
Restrictive Rental Practices and Their Impact on Families
}

\author{
MARY ELLEN COLTEN
}

ROBERT W. MARANS

Institute for Social Research, University of Michigan, Ann Arbor M1 48106, U.S.A.

\begin{abstract}
This article presents the results of a national survey about exclusionary rental policies concerning children. Based on a national sample of renters and the owners or managers of their rental units, the data document the nature, extent and magnitude of exclusionary policies, the attitudes of managers about renting to families with children, the attitudes of renters toward living near children, and the effects that these policies have had on American families. The study shows that exclusionary practices against children have increased in the past decade. The data suggest that exclusionary practices pose a real problem for many American families.
\end{abstract}

\section{Background}

In these times of concern about the demise of the family, there is increasing recognition that the forces which serve to further erode our family structures are far reaching. One force that has received national attention is the changing nature of the housing market and its impact on families.

Home-ownership has become less financially possible for many young families and for an increasing number of single parent households, causing greater demand among families with children for rental housing. At the same time, there has been an increase in numbers of families and individuals without children-e.g., divorced and widowed individuals, elderly persons, and voluntarily childless couples-many of whom do not want the responsibilities and burdens of homeownership. 
As the demand for rental housing increases, landlords can afford to cater to the interests of certain groups and to exclude others. Families with children comprise only about one-third of the rental housing market and thus are a likely target group for exclusion.

Local studies and anecdotal evidence suggest that renters with children are often confronted with exclusionary or discriminatory policies concerning children. These rental policies may exclude children; may limit their numbers, ages, and sexes; may restrict families with children to certain buildings in a complex or certain floors of a building; or may limit families by charging higher rents or requiring a large damage deposit if children are present in the household.

Opponents of exclusionary policies contend that these policies place a burden on families with children, that such families are forced to look longer for housing, to pay higher rents, and to live in less desirable neighborhoods and in lower quality housing units.

Unlike that for race and sex discrimination, no national legislation exists which prohibits discrimination against children. Only a handful of states have legislation on their books prohibiting child exclusion practices and most cities do not have ordinances to prevent it. The policies which do exist often are enforced weakly, if at all. Renters may not even be aware of them, and government officials may not be available to pursue complaints; when they are, punishment imposed on violators is minimal.

Those who protest exclusionary policies assert that, while landlords ought to be able to protect their own interests and those of their present tenants, exclusion of all families with children constitutes true discrimination since it is based on the assumption that all families with children are undesirable.

Exclusionary practices affect not only the families with children but may also eventually have deleterious consequences for the community. For example, the ordinance in Santa Monica, California, prohibiting child exclusion practices notes that: "arbitrary discrimination against families with children leads to the decline of neighborhoods, closure of schools, and reduction of recreational services." Similarly, a study in Atlanta, Georgia, concluded that exclusionary policies have a serious impact on school enrollments and racial balance (Reid, et al., 1979).

Indeed, critics of exclusionary policies have asserted that enactment of these policies is motivated, at least in part, by efforts to practice racial discrimination. Since minority families with children are overrepresented in the rental housing market relative to their proportion of the population, minorities are disproportionately affected by exclusionary policies concerning children. The evidence suggests that these policies 
may also serve to further concentrate minorities in certain areas of cities. Local studies in Dallas and Atlanta have, in fact, indicated that discrimination against children is correlated with racial patterns such that areas of those cities which are comprised predominantly of minority group members have a significantly smaller proportion of units which exclude children than do neighborhoods which are predominantly white (Greene, 1978; Reid et al., 1979).

It is also argued that the failure to prohibit discrimination against children constitutes a legal loophole which allows sex discrimination since female-headed households are also overrepresented in the rental housing market. Ironically, the data suggest that female heads of households are, in fact, very reliable tenants (Anderson-Khleif, 1979).

Others have noted that local ordinances often encourage the exclusion of children. Some municipalities have ordinances which restrict the number of bedrooms allowed in multiple unit dwellings and, at the same time, enforce codes which limit the number of persons who may occupy a unit of a given size. Calvan (1979) has suggested that this is done in an effort to control educational spending in certain areas. It often serves to force families either to rent larger, more costly units or to seek more spacious housing with lower rents and lower quality. In effect, it constitutes a governmental value judgment based on the belief that less crowding in lower quality housing is preferable to more crowding in higher quality units. It is obviously debatable whether or not this is an appropriate area for governmental intervention.

Landlords argue that almost two-thirds of rental households have no children and thus only one-third of rental units need be available to families with children. While this makes sense in theory, it does not necessarily work well in practice since young families, recently married couples, and single parents from recently disrupted marriages are more likely to be presently searching for housing than older child-free persons. In the face of exclusionary practices these groups with children will be able to rent only a portion of the already small number of vacant units.

Still another side of the picture is the perspective of owners and managers of rental housing who argue that children are destructive and therefore renting to families can result in higher maintenance and insurance costs. They also point out that tenants with no children in the household have a right to live removed from the noise, activity, and clutter of children and often exercise that right by deliberately selecting units in places which exclude children. However, members of households without children have been notably absent from the debate over this issue, so landlords have taken the role of expressing what their 
presumed preferences are. In fact, there has been no real information about the actual desires of families without children and the extent to which exclusionary policies play a role in their selection of housing.

\section{Local Area Studies}

Several local studies have attempted to assess the extent and impact of exclusionary policies. Two are particularly noteworthy. The Fair Housing Project (Ashford and Eston, 1979) examined child exclusion rates and types of age restrictions in five California cities (Fresno, Los Angeles, San Diego, San Jose and San Francisco). By surveying rental listings in major newspapers, data were obtained on rent levels, number of bedrooms, whether the apartment was furnished or unfurnished, and the number of units in the building. San Francisco has a local ordinance prohibiting exclusion of families with children and thus the exclusionary rates there were comparatively low. However, in the four other cities, between half and three-quarters of all units surveyed would not allow children of any age. When size of unit was held constant, median rents were higher for places which accepted children. Census and local housing surveys and plans revealed that families with children in those cities are more often inadequately housed, an effect which is particularly significant for female-headed and minority households. Another recent study conducted in Dallas (Greene, 1978) showed that over half of the apartments listed in the yellow pages of the telephone directory exclude children and that another 12 percent restrict the ages and number of children allowed.

The two studies focused on a particular segment of the rental market, i.e., advertised apartments or apartments listed in the telephone directory. Simce a significant portion (one-third) of rental units are singlefamily homes and many rental units are duplexes or in small buildings and are unlikely to be listed in telephome directories, the studies probably explored the situation primarily for larger apartment buildings or complexes.

These studies were prepared in growing communities where the rental housing market was tight and the problems for families with children particularly noticeable and salient. While the data strongly suggest that exclusionary practices may be an obstacle for many families with children in specific locations, no data have been available on the extent to which this is a nation-wide phenomenon. 


\section{A National Survey}

During the winter of 1980 , a survey was conducted by the Survey Research Center of the University of Michigan in order to determine, for the United States as a whole, the extent and nature of policies and restrictions which limit the ability of families with children to find suitable rental housing. Although the study was motivated in part by the results of local area studies, it was not intended to confirm or refute their findings. Rather, its purpose was to identify the magnitude of the problem nationally and to examine factors which might be associated with different policies. The survey addressed four major questions:

(1) What are the rental policies that restrict families with children and how extensive are they?

(2) What types of rental units are most likely to be restricted?

(3) Are restrictive policies increasing?

(4) To what degree are the housing opportunities of families with children limited by various restrictive policies?

The study also explored the extent to which families with children feel that they experienced discrimination or difficulty in finding suitable housing because they have children. Data were produced on the extent to which renters without children seek and demand rental housing which excludes or limits children and how managers justify restrictive policies. The attitudes and preferences of tenants and managers were also examined in order to ascertain the perceived basis for policies and to estimate the impact of possible legislative change.

\section{PROCEDURES}

The data were obtained through telephone interviews with 1007 renters in a national probability sample of rental housing units and 629 owners or managers of those units. The sample of rental units was obtained through a selection of randomly generated telephone numbers which were first screened for housing units and for units which were occupied by renters. The sample of managers was obtained by seeking information on how to contact the managers from the renters themselves [1].

A number of characteristics of the sample of renters should be noted when considering the data about restrictive policies and their impact on families with children. Over two-thirds of the sample (68 percent) have no children living in the household. Thus, restrictive policies are directed at about one third of potential renters. Of those renters with children, four in ten ( 42 percent) have only one child living with them and an additional third (38 percent) have two children. Thus, over 
three-quarters of renters with children have two children or less in the household.

Relative to their proportion in the total population, minority group members are overrepresented in the renter population. Over one-quarter of the respondents were non-white and these minority group members were more likely than white renters to have children in the household. Female-headed households are also overrepresented. Over one-third (37 percent) of all the households with children in the sample are femaleheaded.

It should also be noted that the income of renters is more concentrated in the lower ranges; over 50 percent of the respondents reported total household annual income below $\$ 14,000$. Thus their rental options are constrained by income.

One-fifth ( 22 percent) of the renters in this sample live in single-family dwellings, six in ten ( 60 percent) live in apartment buildings or flats containing two or more units and the remainder live in duplexes, townhouses, condominiums or rental units above garages or in commercial establishments [2]. Families with children are more likely than families without children to rent single-family homes.

Some of the data which follow are presented from the perspectives of both managers and renters; other parts of the data are based on reports from one group or the other. Occasionally, there will be discrepancies between the reports of managers and reports of renters. In part, the discrepancies are attributable to two factors. First, managers' data do not exist for every renter in the sample. Second, some renters are unaware of, and thus tend to underreport the extent of, policies which exclude or restrict children.

\section{NATURE AND EXTENT OF POLICIES AND RESTRICTIONS CONCERNING CHILDREN}

There are numerous management policies and restrictions limiting the ability of families with children to find suitable rental housing. In addition to policies prohibiting the renting of units by families with children in what commonly has been referred to as "adult only" apartments and housing developments, there are restrictions or limitations on the ages of children allowed in units, the maximum number of children or family members, the sharing of a bedroom by children of the opposite sex, and the buildings in complexes or floors in buildings (i.e., the location) where children are permitted. Among each of these restrictions, variations can be found. For example, age restrictions can limit children over a specified age, e.g., no children over two or no 
children over 12 years of age, or they can limit children under a specified age varying from two or three (no preschoolers) to 17 or 18 years of age (no school-aged children). Often, however, age restrictions are not clearly defined and are left to the discretion of the building managers or rental agents.

It should be noted parenthetically that a multiplicity of restrictions could exist and be reported by any single respondent. Nonetheless, the decision was made that for each respondent reporting more than one limitation, only one was recorded. The record limitation was based on severity. For example, restricting children under a certain age was viewed as more severe (and therefore recorded) than limiting the number of children allowed or where within a complex they could live.

In order to ascertain the extent to which these policies exist throughout the United States, the study initially focused on the issue from the perspective of the renters contacted in our national sample. About one in five ( 18 percent) said that there was a policy or restriction governing their rental unit or the rental units around them if they were in an apartment building or complex. Over half of the renters reporting restrictive policies said families with children were not allowed to live in their building or complex. That means that among our total sample of renters, about one in ten ( 11 percent) said they lived in single-family homes, apartment buildings or complexes which excluded children. Additionally, about 8 percent reported living in places that accepted children but with limitations on either their age, the number allowed or where within the building or complex they could live. The remaining 82 percent of the renters said they lived in building or complexes which permit children without any restrictions on their age, number or location.

Another way of considering the magnitude of restrictive practices in the rental housing market is to examine the number of rental units affected by policies or limitations on children. The total number of units represented by the 636 managers is nearly 79,000 . About onequarter ( 26 percent) of these units exclude families with children. Half of the units ( 50 percent) are in places which accept children but impose at least one of the following limitations: limits on the number of children (46 percent of all units), limits on the ages of children (64 percent), prohibitions on the sharing of a bedroom by children of the opposite sex (21 percent), or limitations on where within the building or complex families with children can live (10 percent). Managers of the remainder of the units ( 25 percent) said they accept families with children without any special limitations. Thus, only one quarter of rental housing units are available to families with children with no restrictions. 
In order to target potential solutions to the problem, it is important to know what factors are associated with the likelihood that a rental unit will have restrictions concerning children. Specifically, the study addressed whether restrictive policies tend to vary with the type of dwelling (e.g., single-family home, apartment), size of the unit, the racial composition of the neighborhood, the urbanicity of the setting, the rent of the unit, the quality of the neighborhood, the size of the building or complex in which the unit is situated, the age of the building, and the vacancy rate of the building. A summary of the policy differences for units which vary on these dimensions is presented below.

\section{Policy Differences by Type of Dwelling}

Not surprisingly, single-family homes are much more likely than units in apartments to accept children with no restrictions. While less than one fifth ( 18 percent) of units in apartments accept children with no restrictions, over one half ( 53 percent) of rented single-family homes are available with no restrictions on children.

\section{Policy Differences by Size of Unit}

One-bedroom and efficiency apartments are more likely than units with more than one bedroom to be affected by no-children policies. As can be seen in Table I, only four percent of all rental units having more than two bedrooms are situated in buildings or complexes which exclude families with children. Large units are also more likely to be situated in places which accept children with no restrictions placed on them.

It should be noted that when we take into account the number of places which accept children but prohibit them in units of specific sizes, the percentages of units not accepting children will be greater than those shown in the first row of Table I. As a way of understanding the magnitude of these changes, we first asked managers who accepted families with children but with limitations on their number, "Does the number of children allowed depend on the number of bedrooms in the unit?" Virtually all (96 percent) of the managers answered affirmatively. They were then asked, "How many children would you allow in your bedroom unit?" This question was asked for each sized unit in the building or complex. Within complexes or buildings which do not exclude children, one-bedroom units are often closed to families with children and two-bedroom units are much less frequently restricted. 


\section{TABLE I}

Percentage of all Rental Units Having Policies/Restrictions on Children, By Size of Unit

\begin{tabular}{llllll}
\hline \multirow{2}{*}{ Policy } & \multicolumn{3}{l}{ Size of rental unit } & & \\
\cline { 2 - 6 } & $\begin{array}{l}\text { Effi- } \\
\text { ciency }\end{array}$ & $\begin{array}{l}\text { One } \\
\text { bedroom }\end{array}$ & $\begin{array}{l}\text { Two } \\
\text { bedrooms }\end{array}$ & $\begin{array}{l}\text { Three } \\
\text { or more } \\
\text { bedrooms }\end{array}$ & All \\
\hline No children accepted & $35 \%$ & 42 & 20 & 4 & 26 \\
Children accepted with limitations & 45 & 40 & 54 & 58 & 50 \\
Children accepted with no limitations & 20 & 18 & 26 & 38 & 24 \\
\hline
\end{tabular}

When these units closed to children on account of the unit size are added to units not accepting children at all, as shown in Table I, the percentages increase. Among one-bedroom units, 59 percent rather than 42 percent do not accept children while 24 percent rather than 20 percent of two-bedroom units are not available to families with children.

\section{Policy Differences by Vacancy Rates}

There are no systematic relationships between the vacancy rates in apartment buildings and complexes and the extent to which restrictive policies on children exist. Buildings and complexes with vacancy rates of 10 percent or more are just as likely to prohibit children as buildings and complexes with no vacancies. There is also no consistent relationship between vacancy rate and the proportion of units permitting children but with limitations on their numbers, age, and location. The finding runs counter to claims that low vacancy rates allow landlords to impose restrictive policies.

\section{Policy Differences by Size of Community}

Overall, the size of the community where rental units are located (large urban, small urban, small town) does not significantly influence the proportion of units in places with restrictions concerning children. Similarly, there are no significant differences between cities and suburbs in the proportion of units excluding families with children or imposing limitations on them.

Policy Differences by Racial Composition of Neighborhoods and Apartment Building/Complex

The extent to which restrictive policies exist does vary depending on the racial composition of neighborhoods as reported by renters. Units 
in predominantly white neighborhoods are more likely than rental units in predominantly black neighborhoods to restrict families with children (29 percent versus 18 percent). In racially mixed neighborhoods, 25 percent of the units exclude children.

\section{Policy Differences by Housing and Neighborhood Quality}

It has been suggested that policies/restrictions concerning children are most likely to be found in higher quality neighborhoods and therefore prospective tenants with children are forced to seek housing in neighborhoods of lower quality. In order to test this supposition, the quality of neighborhoods within which rental units were located was assessed. Two indicators of neighborhood quality as perceived by renters were used: one dealing with overall neighborhood satisfaction and the second covering the extent to which selected neighborhood conditions were problematical. At the same time, the renters' housing satisfaction was used as an indicator of housing quality.

When each of these quality indicators was examined for rental units in buildings/complexes with and without restrictions, no relationships were found. The assessments of housing and neighborhood quality of people living in places which do not rent to families with children are comparable to those of people in places which accept children without limitations imposed on them.

When these same relationships were examined for rental units in large cities and in inner city locations, there were also no significant differences. The data do not support the contention that rental units which allow children are of poorer quality and are located in low quality neighborhoods.

\section{Policy Differences by Age of Building/Complex}

Another indicator of residential quality is the age of the structure in which people live. No-children policies are most prevalent among newer (higher quality) units built during the 1970s. Whereas one in three units built since 1970 are in buildings/complexes not accepting families with children, about one in five units in places built earlier have restrictions. The oldest units (i.e., those built prior to 1960) are least likely to have any policy or restriction adversely affecting families with children. Thus residential quality, as reflected by the age of the building, tends to be associated with the presence of restrictive policies against children.

\section{Policy Differences by Size of Building/Complex}

When the percentage of rental units of two or more bedrooms having no-children policies is examined by size of the building, no systematic 
relationships are found between size of building and whether or not children are excluded. However, the size of the building or complex does appear to be related to accepting children but with certain limitations. In particular, the proportion of units affected by limitations of number, sex, and location increases as the size of the complex or building increases.

In summary, exclusion of children does vary according to the type of dwelling, the size of the unit, the age of the unit, and the racial composition of the neighborhood. However, no-children policies do not vary by the vacancy rate of the building, the number of units in the building, the urbanicity of the setting, nor the perceived quality of the neighborhood.

\section{CHANGES IN EXCLUSIONARY POLICIES OVER TIME}

One way of determining whether the prevalence of policies restricting children has been increasing is to compare current rates with estimates of rates at an earlier date. The data covering managers' reports as to when their buildings were constructed and when exclusionary policies went into effect enable us to make this comparison. From the responses of the managers in our sample, it is possible to determine what the policy situation was in 1974 for buildings/complexes which were built by that time. In 1974, 17 percent of all units excluded children while in 198026 percent of all units allowed no children. This substantial increase holds for units of all sizes. Since just under 15 percent of all units in our sample were constructed after 1974, policies associated with newly constructed buildings do not account for the 50 percent increase in the proportion of all units which exclude children.

Another way of exploring the extent to which policies excluding children have increased over time is to ask whether a policy was instituted after the building was constructed. In other words, was there a period during which a no-children building/complex did not have an exclusionary policy? About one third (34 percent) of the exclusionary buildings/complexes constructed between 1970 and 1974 did not have no-children policies in effect until 1975 or later while a similar proportion of buildings constructed before 1970 did not have no-children policies until 1975 or later.

\section{HOUSING OPTIONS FOR FAMILIES WITH CHILDREN}

Estimations have been made of the proportion of all units that would be open (or conversely, not available) to four prototypical families 
given the combination of the variety of restrictions imposed by managers. The prototypical families are (a) a family with one child, (b) a family with two children of the same sex, (c) a family with two children of the opposite sex, and (d) a family with three children.

A family with one child would be allowed to live in nearly two-thirds (64 percent) of all units. This figure drops somewhat for families with two children - about half ( 55 percent) of the units would be open to them. If the two children are of opposite sexes, this figure is reduced to 46 percent. And, not surprisingly, a family with three children can select from only four in ten (41 percent) units in the rental housing market.

The ultimate aim of an examination of rental policies concerning children is to see the impact of these exclusionary policies on the families themselves. It has been suggested that families with children bear the financial burden of exclusionary policies, that on average they pay higher rents in order to find a place to house themselves and their children. In fact, when we compare the mean rent paid by all families with children to that paid by all families without children, families with children do, on the average, pay significantly more. However, when the size of the unit is held constant, there is no significant difference between families with or without children in the average amount of rent paid. It is not irrelevant that almost half ( 47 percent) of the renters without children are people who live alone and that almost nine-tenths ( 85 percent) of the renters with children have three or more persons in the household. When family size is held constant, there also is no significant difference in the mean rent paid by the two groups. Thus, the higher costs of rental housing for families with children is apparently attributable to the greater number of persons in the household and to their renting larger units rather than to the presence of children per se. It is important to note, however, that this analysis does not address the question of whether families with children occupy units of lower quality and thus, although they pay the same amount as families without children, are getting less for their money.

About half ( 49 percent) of the respondents with children in the household reported that when they last looked for a place to live, they found places where they wanted to live but were unable to because of policies about children. This did not vary according to number of children in the family, family income, sex of head of household, or race/ethic background of the family. Thus, exclusionary policies concerning children limited the housing options and probably increased the house-hunting time and cost for nearly half of the respondents, irrespective of their demographic characteristics or family composition. 
The data do not directly support the oft-repeated claim that femaleheaded households and minority groups are more likely to be victims of restrictive practices since, as renters, the groups encountered restrictions in roughly equal percentages. If one is a renter rather than a homeowner, "majority" group membership does not exempt one from the impact of exclusionary practices and, similarly, minority group membership does not appear to exacerbate the difficulty. However, female-headed households and minority households do experience the effects more often simply because they are more likely to be renters.

Over 40 percent of those who had encountered frustration in hunting for a place to rent reported that they had to settle for a less desirable home because they have children. For these families, exclusionary practices affected not only the process of looking but also their ultimate living situation. As a consequence of exclusionary practices, almost one-fifth of all the families with children in the sample are living in homes they consider to be less desirable. The situation is even more extreme for families with three or more children in the household. Almost 30 percent of all of the families with three or more children reported that they have had to settle for a less desirable home. Income, sex of head of household, and race/ethnic background do not appear to be related to whether the family has ended up in what they consider to be a less desirable home.

Nearly half of the respondents who encountered exclusionary practices (or 23 percent of all renters with children) reported feeling that they settled for a less desirable location as a consequence of restrictive practices against children. This effect is particularly strong for families with three or more children. Almost one-third (32 percent) of all families in the sample with three or more children reported baving to live in a less desirable location. A less desirable location may mean a lower quality neighborhood or one which is less convenient for them, e.g., further from work, family, transportation. Regardless of the specifics of desirability, these respondents clearly indicated that they had been victims of exclusionary practices.

Similarly, low income respondents were also more likely to report that they had to settle for a less desirable location. However, sex of head and race/ethnic background do not appear to relate to reports of settling for a less desirable location as a result of exclusionary policies.

In sum, almost half of the families with children reported having encountered disappointment or difficulty in finding housing as a consequence of policies about children, and the situation has a particularly negative impact on families with three or more children and those in the lower income brackets. Families with three or more children have 
been forced to live in what they see as lower quality homes in less desirable neighborhoods; families with lower incomes have sacrificed neighborhood quality or preference more than housing quality.The policies, then, affect more families than the percentage of places having restrictions would lead one to suspect initially. The data suggest that this impact is not insignificant.

\section{RENTERS' ATTITUDES TOWARD LIVING NEAR CHILDREN}

One of the justifications offered by managers for the promulgation of policies restricting children is that many tenants without children in their own households have a clear preference for living in places which exclude children. It is often contended that persons without children select housing specifically to avoid children and that they would move if children were allowed to live in their buildings. So, it is also an issue of pitting the rights and desires of households with children present against the rights and desires of those with no children. Nearly onequarter ( 24 percent) of renters without children in the household did report that they have reasons why they prefer not to live near children. Of the reasons given, noise was by far the most frequently stated, with over half ( 55 percent) of the mentions falling into this category. Less than one-fifth (17 percent) of the responses had to do with destructiveness, property damage or pranks. One out of ten responses focused on the lack of supervision by parents, while one out of twenty had to do with clutter of children's play paraphernalia. A small group (4 percent) mentioned that they liked the amenities, e.g., social advantages, associated with an adults-only setting, while an equal number simply stated that they disliked children.

Of particular interest to policy-makers and managers is whether people select apartments on the basis of whether or not children live there and what people who live in buildings with no children would do if children moved in. In order to address these issues, respondents living in buildings with no children were asked two questions: (1) "Did you choose to live in your building because children weren't living there?" and (2) "Would you move out if families with children were allowed to live in your building?" [3].

One-quarter of respondents without children said they have reasons to prefer not to live near children and one-fifth of those living in buildings which have no children in them chose their building for that very reason. However, 80 percent of those living in buildings with no children would not move if families with children were allowed to move in. Thus, while a substantial minority of respondents express pref- 
erences for or have selected living situations based upon the absence of children, the vast majority of renters in this sample would take no action if the policies or practices concerning children in their building were to change.

\section{MANAGERS' ATTITUDES TOWARD CHILDREN}

Those who make decisions about whether to exclude or limit children from rental housing do so on the basis of some rationale. The managers in this sample were presented with a list of possible problems associated with renting to children and asked if they thought each was a problem in general. Higher maintenance costs was seen as the most problematic aspect, with four-fifths ( 81 percent) of managers reporting that it was a general problem in renting to families with children. Next most frequently seen as a problem was unsupervised children (73 percent), followed by noisy children ( 69 percent), neighbors who complain (61 percent), too much clutter ( 57 percent), and teenage parties ( 56 percent). Higher insurance costs was endorsed as a problem in renting to children by only 38 percent of the managers. Managers of buildings or complexes not accepting children are twice as likely as managers of buildings/complexes accepting children to view each item as problematical. Thus, those managers who are presently dealing with children in their buildings, whether or not by their own choice, do not perceive themselves as having experienced much difficulty.

Over one-half ( 54 percent) of managers think that families without children are bothered by children in the neighborhood while less than one-fourth of such families actually reports that they are or think they would be bothered by children. Thus the belief that policies are needed for the comfort of tenants far exceeds the desires of the tenants themselves.

\section{Summary}

The national survey revealed that exclusionary policies concerning children are varied and extensive. Over a quarter of rental units exclude children, half of rental units are in places which accept children but impose restrictions on the number of children, ages of children, sharing of bedrooms by children of the opposite sex, or where children can live within a particular building or complex. There is a relationship between the extent of these practices and qualities of the units, such that smaller units, units in predominantly white neighborhoods, units in larger 
buildings or complexes, and newer units are more likely to be subject to exclusionary or limiting policies. These policies have definitely become more common in recent years.

Families with children do report having confronted these restrictive practices and many report having had to settle for housing they consider to be less desirable or convenient. While female-headed and minority renter families are no more likely than other renter families to have encountered restrictions, the greatest burden appears to fall on low income families and families with three or more children.

While a quarter of renters without children would prefer not to live near children, only one-fifth of renters presently living in places without children would move if families with children were permitted to live there. By contrast, over one-half of managers believe that renters without children are bothered by the presence of children.

Thus, while no-children policies clearly limit the rental options of families with children, they do not appear to reflect the needs or demands of the majority of renters without children. Since these policies which affect many American families appear to be becoming increasingly pervasive, they warrant closer scrutiny. The results of our study provide the foundation for further public policy debate.

\section{Notes}

I For a detailed description of the sample and data collection procedures, see Marans and Colten (1980).

2 For the analyses reported, we have combined renters living in townhouses and duplexes with those living in apartments.

3 In interpreting these data, it is important to remember that this question elicits only whether or not people have any reasons why they might prefer not to be near children, but does not reflect their actual or intended behavior.

\section{References}

Anderson-Khleif, S. (1979). "Strategies, Problems, and Policy Issues for Single Parent Housing." Prepared for the U.S. Department of Housing and Urban Development Ashford, D. and Eston, P. (1979). "The Extent and Effects of Discrimination Against Children in Rental Housing: A Study of Five California Cities." Santa Monica, Ca.: Fair Housing Coalition, Inc.

Calvan, R. (1979). "Children and families: The latest victims of exclusionary land use practices," Challenge! 10: 26-28.

Greene, J.G. (1978). "An Evaluation of the Exclusion of Children from Apartments in Dallas, Texas." Dallas, Tx.: JG \& Associates.

Marans, R.W., and Colten, M.E. (with R.M. Groves and B. Thomas) (1980). Measuring Restrictive Rental Practices Affecting Families with Children: A National Survey. Washington, D.C.: U.S. Government Printing Office.

Reid, C., Keating, A., and Long, L. (1979). Patterns of Discrimination Against Children in the Metro-Atlanta Area. Atlanta, Georgia: HOPE for Children. 